\title{
O EMBATE DISCURSIVO EM TORNO DA SABEDORIA NA PRIMEIRA CARTA DE PAULO AOS CORÍNTIOS A PARTIR DE UMA PERSPECTIVA FOUCAULTIANA *
}

\author{
Alaina Garcia Margiotti \\ Alfredo dos Santos Oliva
}

\begin{abstract}
Resumo: Este artigo propõe uma análise das estratégias discursivas de Paulo frente aos seus oponentes na Primeira Carta aos Coríntios, por meio das oposições antagônicas que o apóstolo fez da "sabedoria do mundo", pautada no discurso racional, e da "sabedoria de Deus", na mensagem redentora da cruz de Cristo. Com auxílio do método genealógico foucaultiano, pretendemos identificar as condições de verdade do discurso do autor, bem como do de seus opositores, a fim de compreender como o apóstolo, utilizando-se de sua autoridade, teria empreendido técnicas de ordenamento e exclusão das práticas discursivas com as quais se deparou na comunidade, separando o que considerou verdadeiro do falso.
\end{abstract}

Palavras-chave: Cristianismo Paulino; Corinto Romana; sabedoria; embate discursivo; autoridade.

\section{NOR MADNESS OR REASON: THE DISCURSIVE CLASH AROUND THE WISDOM IN PAULO'S FIRST LETTER TO THE CORINTHIANS}

\footnotetext{
* Recebido em: 30/09/2020 e aceito em: 12/12/2020.

** Mestranda em História Social pela Universidade Estadual de Londrina, na linha História e Linguagens. Participante do projeto de pesquisa intitulado "Usos do Conceito de Escrita de Si de Michel Foucault na Análise de Correspondência Pessoal: Estudos de Caso Sobre o Apóstolo Paulo, o Pintor Vincent Van Gogh e o Psiquiatra Carl Gustav Jung". E-mail: alaina.garcia@outlook.com.br.

*** Professor associado da Universidade Estadual de Londrina desde 2007. Doutor em História pela Universidade Estadual Paulista Júlio de Mesquita Filho (2005), com Pós-doutorado em Ciências da Religião pela Universidade Metodista de São Paulo (2017). Coordenador do projeto de pesquisa "Usos do Conceito de Escrita de Si de Michel Foucault na Análise de Correspondência Pessoal: Estudos de Caso Sobre o Apóstolo Paulo, o Pintor Vincent Van Gogh e o Psiquiatra Carl Gustav Jung".
} 


\begin{abstract}
This article proposes an analysis of Paul's discursive strategies against his opponents in the First Letter to the Corinthians, through the antagonistic oppositions that the apostle made of the "wisdom of the world", based on rational speech, and the "wisdom of God", in the message about the redemptive cross of Christ. With the aid of the Foucaultian genealogical method, we intend to identify the truth conditions of the author's speech, as well as that of his opponents, in order to understand how the apostle, using his authority, would have undertaken techniques of ordering and excluding discursive practices he encountered in the community, separating what he considered true from what was false.
\end{abstract}

Keywords: Pauline Christianity; Roman Corinth; wisdom; discursive clash; authority.

A Primeira Carta aos Coríntios é um documento que vem sendo analisado pela exegese bíblica ao longo dos séculos, mas que ainda continua suscitando múltiplas interpretações nos dias de hoje. Todavia, para além de seus objetivos teológicos, há de se ressaltar que também para os historiadores a fonte tem muito a oferecer. Por se tratar de uma correspondência pessoal, a carta se volta para questões práticas do cotidiano de pessoas comuns, que lidaram com a mensagem anunciada pelo apóstolo que viria a se tornar um dos principais nomes da fé cristã. Suas palavras alcançariam uma autoridade muito além da que ele já conquistara perante os membros das comunidades que fundou.

Paulo de Tarso era um judeu da diáspora, que aceitou a messianidade de Jesus de Nazaré, crucificado em Jerusalém alguns anos antes de sua experiência visionária de conversão ao movimento cristão, quando teria sido chamado pelo próprio Cristo Ressurreto para se tornar seu apóstolo (1 Coríntios 15:8). Sem adentrarmos na discussão a respeito do termo "conversão" aplicado a Paulo, destacamos apenas que o caráter místico de sua experiência muito influenciaria seu anúncio de salvação.

O apóstolo fundou várias comunidades nas cidades do Império Romano, com as quais se correspondeu por meio de cartas. Como salienta Brown (2005, p. 58), as cartas de Paulo afinavam-se com uma escatologia iminente, ${ }^{2}$ que não via necessidade de produzir documentos de natureza mais permanente, com ares universais. As cartas - os documentos mais antigos do movimento cristão de que temos conhecimento - funcionavam como o meio de comunicação entre o apóstolo itinerante e os convertidos de cada lugar em que ele havia proclamado Jesus. Esses documentos, por- 
tanto, alinham-se com a expansão geográfica do movimento cristão, não sendo concebidos como tratados teológicos ou sistemáticos, mas como escritos pontuais, com o objetivo de resolver questões imediatas e urgentes percebidas por Paulo em cada comunidade. Cada carta enfatiza determinados aspectos da fé em Jesus em detrimento de outros, os quais não são mencionados provavelmente por não serem uma questão problemática naquela comunidade em específico.

A comunidade de Corinto suscitou variadas questões a serem discutidas por Paulo. Ao longo de 1 Coríntios, o apóstolo denunciou problemas morais (em relação ao comportamento considerado promíscuo de alguns dos membros), sociais (devido às grandes desigualdades que atrapalhavam o convívio do grupo) e, sobretudo, de ordem doutrinária (a ocorrência de rixas e dissensões, que ameaçavam a unidade da comunidade e ainda abriam espaço para o surgimento de "falsas verdades"). Neste artigo, vamos lidar com este último aspecto, mais especificamente com a postura do apóstolo diante da incompreensão do evangelho que anunciou, e com a iminência de outras lideranças surgidas em sua ausência, que passaram a disputar com ele - o líder fundador -, o cobiçado "lugar de verdade" na comunidade de Corinto.

A verdade, na percepção do filósofo francês Michel Foucault, não se constituiria em uma fonte eterna e imutável, mas estaria completamente ligada ao exercício do poder. Quando desenvolveu sua análise genealógica, muito inspirada no pensamento nietzschiano, o autor investigou os regimes de verdade de cada contexto, com o intuito de identificar os fenômenos responsáveis por regular e impedir que determinados discursos sejam ditos, para que outros possam emergir e se perpetuar.

Em A ordem do discurso (1996), Foucault explica que a abordagem crítico-genealógica se ocupa em descobrir os mecanismos de controle, ou as regras de criação, circulação e interdição dos discursos na esfera social. Ao dimensioná-los historicamente, a abordagem visa identificar as condições de possibilidade que permitiram o aparecimento e a perpetuação das "verdades" estabelecidas, e assim constatar tanto as condições de elevação e perpetuação dos discursos verdadeiros quanto a marginalização dos de oposição, que passariam por um processo de sufocamento e exclusão. Diante disso, o autor propõe uma abordagem que reconheça as engrenagens que teriam possibilitado a eleição de determinados preceitos, que aca- 
bariam por se tornar padrões tão consolidados a ponto de serem tidos como verdades absolutas e incontestáveis.

Dividida nos conjuntos crítico e genealógico, essa abordagem visa buscar tanto os mecanismos de recobrimento quanto os de perpetuação dos discursos, utilizando-se desses dois aspectos inseparáveis: "A crítica analisa os processos de rarefação, mas também de reagrupamento e de unificação dos discursos; a genealogia estuda sua formação ao mesmo tempo dispersa, descontínua e regular" (FOUCAULT, 1996, p. 65-66).

Sem se preocupar em descrever os discursos ou em buscar suas origens, Foucault parecia mais interessado em identificar as relações de força responsáveis por recobrir alguns discursos e elevar outros, o que levaria ao ressurgimento dos tidos como verdadeiros e ao sufocamento dos tidos como falsos. Neste ínterim, segundo o autor, a análise se utilizaria tanto de mecanismos externos de controle do discurso (a interdição, a separação/ rejeição e a oposição verdadeiro e falso), como dos internos (a autoria, o comentário e a disciplinarização).

Dentre eles, destacamos a função autor. Para o teórico, o nome do autor não seria uma simples assinatura, mas exerceria uma atuação no exercício de poder dos discursos em sociedade, desempenhando papel preponderante. A autoria reúne as funções de relacionar, opor e classificar os diferentes textos, estabelecendo entre eles diferenças ou filiações, de modo a identificar o que pertenceria e o que não pertenceria a um mesmo autor.

Enfim, o nome do autor funciona para caracterizar um certo modo de ser do discurso: para um discurso, o fato de haver um nome do autor, ofato de que se possa dizer "isso foi escrito por tal pessoa", ou "tal pessoa é o autor disso", indica que esse discurso não é uma palavra cotidiana, indiferente, uma palavra que se afasta, que flutua e passa, uma palavra imediatamente consumivel, mas que se trata de uma palavra que deve ser recebida de uma certa maneira e que deve, em uma dada cultura, receber um certo status. (FOUCAULT, 2009, p. 273-274)

O discurso, portanto, seria recebido conforme o lugar que seu autor ocupa em uma dada cultura, de acordo com o prestígio ou status que seu nome adquiriu através das complexas relações de poder sedimentadas nas conjunturas históricas. Diante disso, o autor se pergunta: 


\section{[...] segundo que condições e sob que formas alguma coisa como um}

sujeito pode aparecer na ordem dos discursos? Que lugar ele pode ocupar em cada tipo de discurso, que funções exercer, e obedecendo a que regras? Trata-se, em suma, de retirar do sujeito (ou do seu substituto) seu papel de fundamento originário, e de analisá-lo como uma função variável e complexa do discurso. (FOUCAULT, 2009, p. 287)

As palavras de Paulo, em Corinto, objetivavam cumprir uma função coercitiva, que se legitimou quando o apóstolo afirmou ter sido escolhido pelo próprio Cristo Ressuscitado (1 Coríntios 15:8). Além desse artifício, Paulo relembrou seu papel de fundador da comunidade de Corinto, o que também lhe conferia autoridade, justificando sua qualidade de apóstolo (1 Coríntios $3: 6 ; 15: 1$ ). Paulo, portanto, ocuparia um lugar de fala privilegiado em relação aos outros, devido a esses componentes preexistentes, que promoviam a eficácia de seu discurso legitimador.

A ação proselitista de Paulo também se alinhava à escatologia iminente em que estava imerso. A Boa-Nova do evangelho deveria ser proclamada a fim de salvar o maior número possível de pessoas, sem distinção entre judeus ou gregos, escravos ou livres, homens ou mulheres (Gálatas 3:28). Como destaca Cuvillier (2005, p. 38-39), Paulo viajou pelo Mediterrâneo e pelas estradas romanas, peregrinando pelas cidades, em um período de estabilidade conhecido como Pax Romana. Utilizando-se das vias de comunicação viabilizadas pelo Império em expansão, fossem elas rotas marinhas ou terrestres, Paulo fazia parte dos inúmeros viajantes que percorriam as populosas cidades submetidas a Roma, do Oriente ao Ocidente.

Corinto era uma próspera metrópole do Império Romano. Devido ao seu lugar estratégico, a cidade era um importante ponto para a difusão do evangelho, o que Paulo logo identificou. O porto de Corinto era um dos mais movimentados da época, onde transitavam pessoas de diferentes localidades. Como alude N. Bookidis (2005, p. 141), a antiga cidade grega fora destruída durante a campanha imperial pelo general romano Lúcio Múmio, em 146 a.C., mas reconstruída um século depois por Júlio César, tornando-se uma tradicional colônia romana, povoada por veteranos de guerra e escravos libertos. Em meio às ressignificações da cultura grega pelos romanos, templos e santuários foram reerguidos e tiveram seus cultos retomados pelos novos habitantes. 
Quando pregou em Corinto, Paulo se deparou com uma infinidade de cultos politeístas de matriz grega, romana ou oriental, que coexistiam ao lado do modo de vida dos judeus da diáspora, que possuíam sinagogas nas cidades do Império. Segundo Atos, Paulo teria se dirigido a uma sinagoga em Corinto para pregar a fé no Messias Jesus, com o intuito de persuadir não apenas seus compatriotas judeus, mas também de atrair os não-judeus. Além destes, um terceiro grupo é mencionado nesse livro posterior às cartas de Paulo, os "tementes a Deus", que, segundo a tradução de Gingrich (1984, p. 187), podem ser caracterizados como “[...] adoradores de Deus, gentios não-convertidos que foram atraídos pela religião de Israel mas não assumiam todas as obrigações da lei judaica". Esse grupo, como salienta Crossan e Reed (2007, p. 9), teria sido o enfoque da pregação de Paulo, que via nesses gentios simpáticos ao judaísmo potenciais convertidos ao movimento cristão, uma vez que não seriam totalmente indiferentes à mensagem messiânica, nem tão resistentes como um judeu propriamente dito - ainda que este último aspecto não seja um empecilho para a conversão ao movimento cristão, como vemos no caso do próprio Paulo, que era um fariseu convicto.

No entanto, a ação proselitista de Paulo, como ressalta Dunn (2017, p. 178), diferia da fé judaica, que, de regra, não possuía um ideal missionário, apesar de acolher os tementes a Deus e prosélitos. O propósito missionário se constituiu em uma característica da difusão do evangelho cristão, a Boa-Nova que precisava ser anunciada pelos apóstolos de Cristo antes de seu retorno, na Parúsia. Ainda assim, judeus pregadores de uma mensagem apocalíptica também existiam nesse contexto, como o próprio Jesus e João Batista.

Já Paulo, de acordo com as informações reunidas por Murphy-O'Connor (2015, p. 43-44), evangelizou Corinto durante cerca de um ano e meio, entre os anos de 50 e 51, chegando à cidade provavelmente por meio de uma rota terrestre, após a fracassada tentativa de evangelizar Atenas. Em Corinto, o apóstolo teria se estabelecido com o casal Priscila e Áquila, judeus vindos de Roma que já haviam se convertido à fé no Messias Jesus, e que, segundo Atos 18:3, foram companheiros de Paulo não apenas na obra da evangelização, mas também no ofício de fabricação de tendas - algo que seria bastante útil na cidade que sediava os Jogos Ístmicos.

Após o sucesso de Corinto, Paulo teria passado por Jerusalém, Antioquia e Galácia, chegando a Éfeso no ano seguinte, sendo que durante sua 
estadia nessa cidade, de 52 a 54, teria escrito o documento que depois ficou conhecido como Primeira Carta aos Coríntios. Após sua saída de Éfeso, foi a caminho da Macedônia, e ainda fez uma outra visita a Corinto (2 Coríntios 12:14; 13:1-2). Além das duas epístolas posteriormente canonizadas, a correspondência com Corinto teria sido mais extensa: Paulo se refere a uma carta anterior a essa (1 Coríntios 5:9), além de referenciar a existência de outras (2 Coríntios 2:3-9; 7:8-12; 10:10). Segundo Machado (2015, p. 155), as relações epistolares com a comunidade teriam se estendido de 50 a 57 , demonstrando que os problemas da comunidade não eram dos mais simples.

A incompreensão de seu anúncio da morte redentora ${ }^{3}$ de Cristo pelos coríntios parece ser o problema que perpassa toda a epístola. Ao longo do primeiro capítulo da carta, Paulo reitera que a crucificação de Jesus estava sendo caracterizada negativamente por dois grupos distintos - os judeus e os gentios ou gregos ${ }^{4}$-, que estavam chamando sua pregação de "escândalo" e "loucura", respectivamente. Paulo anunciava a Boa-Nova da morte e ressurreição de Cristo; então, a cruz não seria um simples instrumento de tortura e condenação, utilizado pelos romanos para punir seus criminosos e dissidentes. Em Paulo, ela se transformaria em "[...] sabedoria proveniente de Deus, justiça, santificação e redenção" (1 Coríntios 1:30).

Ainda no primeiro capítulo, o apóstolo avança em sua crítica ao dizer que membros de origem judaica requeriam sinais para a compreensão da mensagem que anunciava, à medida que outros, de origem não-judaica, ansiavam por uma explicação minimamente lógica para compreendê-la (1 Coríntios 1:22-23). Paulo parece constatar que os judeus esperavam uma experiência concreta que assegurasse a verdade de sua pregação, enquanto os versados na cultura grega depositavam suas expectativas em um discurso racional, que oferecesse uma explicação plausível e convincente.

Embora também se refira ao "escândalo" da cruz, o apóstolo pareceu se preocupar mais com o termo "loucura", usado, segundo ele, por membros de origem gentia. Paulo contra-ataca, utilizando a mesma palavra que seus críticos: "loucura", para Deus, seria o inverso do que era "loucura" para o mundo, e vice-versa. Esse termo aparece seis vezes ao longo da epístola, geralmente apresentado em contraste com a sabedoria. Embora existam outros sinônimos para "loucura" no mundo antigo, no texto em grego dos primeiros capítulos de 1 Coríntios, encontramos a palavra mōría, que se traduz por "loucura, insensatez, tolice" (GINGRICH, 1984, p. 138). 
Vale ressaltar que a palavra em questão, como destaca Vieceli (2014, p. 49-50), poderia ser associada a diferentes fatores na Antiguidade Clássica, exceto à anacrônica ideia moderna de doença mental. Por essa percepção, segundo a autora, aqueles que perdiam a razão poderiam estar sofrendo conflitos interiores, causados pelas paixões humanas, ou, ainda, poderiam estar sendo punidos pelas divindades, que, assim, os castigavam por algum motivo. Independentemente das causas, a loucura a que Paulo se refere parece se aproximar mais de um comportamento tido como sem sentido algum, ou seja, que não se encaixaria socialmente, ocasionando repulsa das pessoas em geral, por ser considerado, no mínimo, "estranho".

A utilização do termo demonstra a existência de uma situação difícil que estaria causando contendas entre os membros da comunidade. Essas discordâncias acabaram gerando divisões na comunidade e ameaçando sua unidade. Tanto é que, a seguir, Paulo parece conectar o problema das divisões à caracterização pejorativa de seu evangelho pelos grupos que se reuniam em torno de Cefas e Apolo (1 Coríntios 1:11-13). No capítulo 3, volta a mencionar as divisões, mas se atém ao segundo, assegurando que ambos são cooperadores na obra de Cristo, não rivais, e que Apolo havia dado continuidade à sua pregação (1 Coríntios 3:4-7).

Como reitera Murphy-O'Connor (2015, p. 284-285), as divisões que Paulo denuncia já no início da epístola revelam a existência de no mínimo três facções lideradas pelos três nomes mencionados - Apolo, Cefas e o próprio Paulo, o que estava acarretando inúmeros problemas na ekklèsía de Corinto. Para o autor, a impossibilidade de se reunirem em uma única casa, devido ao grande número de membros da comunidade, teria contribuído para a formação de tais rixas e dissensões.

Mesmo que Apolo e Cefas não fossem seus oponentes, as divisões que se formaram em torno deles teriam incomodado Paulo. Sem culpá-los propriamente, o apóstolo se prontificou a corrigir e instruir aqueles que estavam confusos acerca das consequências da Boa-Nova de Cristo, e tudo que girava em torno dela - como questões práticas em relação ao comportamento na assembleia e na vida particular, e também quanto a certas convicções dos fiéis, como existência da ressurreição dos mortos.

Na interpretação de H. Koester (2005b), J. Murphy-O'Connor (2015) e S. Patterson (2013), os opositores de Paulo, em vez de depositarem sua confiança no evangelho da cruz, se amparavam em palavras de sabedoria 
para a compreensão da salvação promovida por Cristo. Na tese de Murphy-O'Connor (2015, p. 287-289), esses opositores, os "espirituais", teriam sido influenciados pela interpretação helenizada do judaísmo de Fílon de Alexandria. O autor se baseia nas informações de Atos 18:24, que descreve a atividade e os ensinamentos de Apolo, que, segundo o texto, era um judeu alexandrino eloquente que conhecia muito bem as Escrituras, e que ensinava com exatidão o que se referia a Jesus.

Para Murphy-O’Connor (2015, p. 286), a pregação anti-intelectual de Paulo, quando antepõe a sabedoria do mundo à de Deus, estaria intimamente ligada à atividade desse grupo. Composto por uma minoria rica e instruída, os chamados "espirituais" acabavam por exercer influência sobre os demais, ocasionando contestações que levavam às divisões e aos comportamentos que Paulo considerou tanto inadequados quanto prejudiciais para a vivência da comunidade com Cristo. Diante disso, o autor enxerga um tom de zombaria na fala de Paulo, ao ter alegado que seus opositores não conseguiam entender de fato o que viria do Espírito (1 Coríntios 2:14), pois ainda estavam sendo guiados pelas exigências da carne (1 Corintios 3:3-4).

Já na hipótese de Patterson (2013, p. 84) e Koester (2005b, p. 344), esses opositores estariam se baseando nos ditos de Jesus, presentes no Evangelho de Tomé, que, pela percepção dos autores, poderia ser datado, pelo menos em partes, do contexto do apóstolo. O texto apresenta uma soteriologia ${ }^{6}$ diferente da que se vê nos evangelhos posteriormente canonizados e nas cartas paulinas. No Evangelho de Tomé, a superação da morte e a salvação promovida por Cristo não ocorreriam por meio de sua crucificação e ressurreição, mas através da sabedoria presente em suas palavras. Para os autores, o documento encontrado na biblioteca de Nag Hammadi pode se relacionar diretamente com as ideias dos espirituais de Corinto, que pareciam concordar mais com uma interpretação baseada no lógos do que com o evangelho da cruz redentora de Paulo.

A palavra sabedoria aparece 17 vezes na epístola. ${ }^{7}$ No Léxico do Novo Testamento, sophía pode ser definida como "a sabedoria achada entre o povo, quer natural, quer dada por Deus” (GINGRICH, 1984, p. 191). Já na tradução de Preus (2015 p. 369-360), no contexto de fala grega o termo poderia ser utilizado para qualificar uma pessoa de notável habilidade discursiva, cujos ditos ficavam na memória comum. Porém, Preus ressalva que, com o surgimento da filosofia, alguns sábios recusaram esse título, 
alegando não serem seus detentores, preferindo o título de "filósofos", ou seja, "amantes da sabedoria". A partir de então, a palavra passou a ter diferentes conotações no mundo grego antigo, de acordo com as reflexões de cada pensador, o que culminaria em definições variadas entre adeptos do platonismo, aristotelismo, estoicismo, etc., o que impede uma tradução única e precisa.

Também a cultura judaica mantinha uma relação com o conceito de sabedoria. De acordo com Koester (2005a, p. 243), a tradição remonta à época de Salomão, sobrevivendo e reaparecendo em diferentes textos ao longo dos séculos. No período helenístico, a sabedoria passou a desempenhar uma função nas especulações cosmológicas e escatológicas dos textos apocalípticos, fornecendo orientações ao indivíduo que almejava a salvação, propondo a cada ser humano encontrar seu lugar no mundo, garantindo a ordem e superando o caos. Os ensinamentos de sabedoria postulavam a origem e o destino divino do homem, mas para que esse estado de divindade fosse de fato alcançado, seria necessário que cada um buscasse a sabedoria em suas trajetórias, por meio de uma vida sábia e justa. Em textos como a Sabedoria de Salomão, Daniel, na literatura de Enoque ou na filosofia de Fílon de Alexandria, a moralidade aparece como consequência da sabedoria presente na Lei, que passou a ser "[...] o caminho para a realização do destino divino dos seres humanos" (KOESTER, 2005a, p. 245).

No mais, apenas recorremos a poucos exemplos para salientar que variados discursos tinham potencial para incomodar Paulo, justamente por tirarem o protagonismo do evangelho da cruz. Seus oponentes estariam creditando a salvação a outros mecanismos, aparentemente mais voltados às palavras de sabedoria do Cristo Jesus. Como demonstra Koester,

Evidently, Paul does not allow such sayings to carry the authority of Jesus, and thus he denies the Corinthians the right to rely on such sayings. For Paul, the mystery that is being revealed is never a saying of Jesus but the message of the cross (1 Cor 1:17-18). Although Paul knows such sayings of Jesus, they are never referred to as saving authorities. His message of Christ crucified does not permit Jesus to stand as an authority for sayings that have the power to save. (KOESTER, 2005b, p. 345)

Os opositores de Paulo, como vimos, poderiam se fundamentar em inú- 
meros discursos para construírem suas identidades cristãs, baseados naquilo que considerassem como "palavras de sabedoria”. Porém, mais do que rastrear esses discursos de oposição, nosso objetivo é caracterizar as condições que elevaram o discurso paulino ao lugar de verdade na comunidade de Corinto, no momento em que a carta foi escrita e endereçada. Vale ressaltar que, neste artigo, não nos voltamos para o período em que a epístola foi canonizada, séculos depois, o que movimentou outras complexas relações de poder.

Mas voltemos ao nosso enfoque contextual: a Corinto de Paulo e dos membros da comunidade cristã da década de 50 do primeiro século. Em nossa perspectiva, o conflito discursivo entre o apóstolo e os dissidentes estaria situado em sua contraposição da "sabedoria do mundo" à "sabedoria de Deus", quando pareceu convergir o discurso que considerou como verdadeiro dos que julgou falsos:

Estive entre vós cheio de fraqueza, receio e tremor; minha palavra e minha pregação nada tinham de persuasiva linguagem da sabedoria, mas eram uma demonstração de Espírito e poder, a fim de que a vossa fé não se baseie na sabedoria dos homens, mas no poder de Deus.

No entanto, é realmente de sabedoria que falamos entre os perfeitos, sabedoria que não é deste mundo nem dos príncipes deste mundo, votados à destruição. Ensinamos a sabedoria de Deus, misteriosa e oculta, que Deus, antes dos séculos, de antemão destinou para a nossa glória. Nenhum dos príncipes deste mundo a conheceu, pois, se a tivessem conhecido, não teriam crucificado o Senhor da Glória. (1 Coríntios 2:3-8)

Paulo salienta que suas palavras revelavam uma demonstração do poder de Deus, desconhecido aos olhos do mundo, que crucificou Jesus. Na visão de Crossan e Reed (2007, p. 305), o apóstolo criticou a postura de seus opositores por estar em consonância com todo o sistema social mundano, que promovia as desigualdades, imoralidades e sofrimentos na Terra. Segundo os autores, esse comportamento estaria alinhado com as forças que executaram Jesus, representadas pelos poderes então vigentes, que atuavam de acordo com a "sabedoria do mundo", considerada nula por Deus. Destarte, quando não enxergavam a sabedoria de Deus presente na cruz, os coríntios 
estariam se deixando levar por esse enganoso discurso, que cada vez mais os afastava da graça do Criador.

Outro detalhe que nos chama atenção nesses versículos é a caracterização da sabedoria de Deus como misteriosa e oculta, que, por não se restringir a uma temporalidade, duraria para sempre, por toda a eternidade. Já o pensamento lógico, por outro lado, seria inadequado para acessá-la, pois ele, assim como qualquer outro recurso mundano, estaria condenado à destruição. Os oponentes de Paulo, em sua própria percepção, estariam apresentando uma versão baseada nessa lógica mundana, que, embora parecesse sábia aos olhos do mundo, seria loucura diante de Deus:

Ninguém se iluda: se alguém dentre vós julga ser sábio aos olhos deste mundo, torne-se louco para ser sábio; pois a sabedoria deste mundo é loucura diante de Deus. Com efeito está escrito:

Ele apanha os sábios em sua própria astúcia.

E ainda:

O senhor conhece os raciocínios dos sábios; sabe que são vãos.

Por conseguinte, ninguém procure nos homens motivo de orgulho, pois tudo pertence a vós: Paulo, Apolo, Cefas, o mundo, a vida, a morte, as coisas presentes e as futuras. Tudo é vosso; mas vós sois de Cristo, e Cristo é de Deus. (1 Coríntios 3:18-23)

Os tradutores da Bíblia de Jerusalém relacionam essas citações de Paulo a duas passagens da Bíblia Hebraica - Jó 5:13 e o Salmo 94:11, que apresentam máximas parecidas com sua crítica aos que se engrandeciam por se autointitularem sábios. Paulo, desse modo, se voltou ao seu conhecimento das Escrituras para demonstrar que elas também denunciavam um comportamento soberbo, que não agradaria a Deus.

Isso demonstra que Paulo não recorreu apenas à sua autoridade apostólica, baseada em sua experiência visionária, para defender seu anúncio de salvação. O apóstolo também se esforçou em demonstrar que seu evangelho estaria de acordo com as Escrituras, tanto é que se referiu a elas várias vezes em seus escritos. Como demonstra Dunn (2008, p. 210), há cerca de uma centena de citações explícitas das Escrituras em suas cartas, sendo que mais de noventa por cento delas estão presentes nas cartas principais (Romanos, Gálatas, 1 e 2 Coríntios), nas quais Paulo desenvolveu mais completamente seus argumentos. 


\section{Conclusões}

Em síntese, compreendemos a oposição feita por Paulo entre a "sabedoria do mundo" e a "sabedoria de Deus" como um indício de que o lugar de verdade estava em disputa na comunidade de Corinto. Para atacar seus adversários, o apóstolo argumentou que qualquer palavra de sabedoria, pautada em artifícios de linguagem, jamais se igualaria ou superaria o mistério da sabedoria da cruz, em sua compreensão, a verdadeira Boa-Nova da salvação.

Paulo defendia que fora enviado aos coríntios para levar a verdadeira mensagem de sabedoria, que estaria presente na cruz de Cristo. Para ele, a cruz assumira um significado revolucionário ao transformar-se no meio pelo qual o Messias se sacrificou em razão dos pecados da humanidade, para promover a ação salvadora de Deus para com os homens. Para assimilar tudo isso, no entanto, os crentes não deveriam recorrer ao pensamento lógico, que não seria apenas inadequado, mas também prejudicial à assimilação do que o apóstolo julgava ser o verdadeiro significado da cruz de Cristo.

De acordo com as proposições teóricas de M. Foucault, compreendemos que Paulo teria empreendido técnicas de coordenação dos discursos para contornar os problemas com os quais se deparou na comunidade. Para tanto, teria interditado aquilo que não poderia ser dito, para depois separá-lo de seu discurso, e assim, consequentemente, classificar o verdadeiro e o falso. Por essa percepção, para que um discurso seja considerado verdadeiro, tais pressupostos precisariam estar dentro de regras preeestabelecidas que o considerassem como tal. E isso não apenas para que pudesse ser compreendido, mas, sobretudo, para ser consagrado como verdade.

Utilizando-se de sua autoridade, Paulo tentou legitimar o seu discurso com o argumento de que o comunicava com a sabedoria de Deus, e não do mundo. Além de recorrer ao seu conhecimento das Escrituras, o apóstolo anunciava que seu evangelho havia sido comunicado a ele pelo próprio Cristo; assim, sua pregação estaria baseada nessa experiência, e não em qualquer habilidade retórica que pudesse empreender. Mesmo que o discurso de seus oponentes parecesse mais agradável, por se pautar em uma boa retórica, ele não via grande valor nisso - tanto é que admitiu não ter recorrido à sabedoria da linguagem em sua pregação (1 Coríntios 2:1-4). Paulo apostava era na fé que teria recebido do próprio Cristo, quando o chamou para ser seu apóstolo. 
Por fim, ainda ressaltamos que tanto os conceitos de loucura quanto os de sabedoria são transpassados pela historicidade, uma vez que constituídos mediante as relações de poder de um dado contexto. A definição de loucura, para Paulo, é diferente da de seus opositores. Sua pregação seria assim adjetivada diante do pensamento racional, pois a salvação não poderia ser alcançada por meio de palavras de sabedoria pautadas na razão filosófica, mas na morte e ressurreição de Cristo.

Por outro lado, como salienta J. Dunn, o aspecto místico do cristianismo de Paulo não o levou a descreditar o uso da razão na vivência cristã. $\mathrm{O}$ culto deveria incluir mente (noûs) e coração (kardía), ou seja, razão e emoção, em equilíbrio. Segundo o autor, Paulo valorizava tanto o "eu pensante" quanto o "eu que experimenta (sente), que motiva" (DUNN, 2008, p. 108). O discernimento seria muito útil para a tomada de decisões éticas na vida do crente, mas não seria o suficiente: a graça de Deus deveria penetrar no mais íntimo da pessoa, ser profundamente sentida, experienciada.

A mensagem de salvação de Paulo pressupõe muito mais um conteúdo místico do que racional, que coincide com sua experiência extática de conversão. A verdade de Paulo se edificou em consonância com o seu perfil visionário, de pregador versado no pensamento apocalítico. $\mathrm{O}$ evangelho da cruz não seria, para ele, nem loucura, nem razão, mas sabedoria de Deus, possível de ser alcançada apenas por meio de uma experiência mística de fé e entrega ao Cristo Ressuscitado, que a razão humana jamais conseguiria dimensionar.

\section{Documentação escrita}

GORGULHO, G. S.; STORNIOLO, I.; ANDERSON, A. F. (orgs). Bíblia de Jerusalém - Tradução do texto em língua portuguesa diretamente dos originais. Paulus: São Paulo, 2010.

NESTLE-ALAND. Novum Testamentum Graece. Based on the work of Eberhard and Erwin Nestle. Edited by Barbara and Kurt Aland, Johhanes Karavidopoulos, Carlo M. Martini, Bruce M. Metzger. 28th Revised Edition. Stuttgart: Deutsche Bibelgesellschaft, 2012.

\section{Dicionários}

GINGRICH, F. Wilbur. Léxico do N. T. Grego/Português. Revisado por Frederick W. Danker. Trad. Júlio P. T. Zabatiero. São Paulo: Edições Vida Nova, 1984. 
PREUS, Anthony. Historical Dictionary of Ancient Greek Philosophy - Second Edition. London: Rowman \& Littlefield, 2015.

\section{Referências bibliográficas}

BOOKIDIS, Nancy. Religion in Corinth: 146 B.C.E. to 100 C.E. In: SHOWALTER, Daniel N.; FRIESEN, Steven F. (orgs.). Urban Religion In Roman Corinth: Interdisciplinary Approaches. Cambridge: Distributed by Havard University Press for Havard Theological Studies Havard Divinity School, 2005, p. 141-164. BROWN, Raymond. Uma introdução ao Novo Testamento. São Paulo: Paulus, 2005.

CROSSAN, Jhon D.; REED, Jonathan L. Em busca de Paulo: como o apóstolo de Jesus opôs o Reino de Deus ao Império Romano. Trad. Jaci Maraschin. São Paulo: Paulinas, 2007.

CUVILLIER, Elian. Paulo: A humanização de Deus. Trad. Marly N. Peres. História Viva, São Paulo, n. B, v. 17, p. 38-41, mar. 2005.

DUNN, James D. G. A teologia do apóstolo Paulo. Trad. Edwino Royer. São Paulo: Paulus, 2008. 2017.

. Jesus, Paulo e os evangelhos. Trad. Hélio Schneider. Petrópolis: Vozes,

FOUCAULT, Michel. A ordem do discurso: Aula inaugural no Collége de France pronunciada em 2 de dezembro de 1970. Trad. Laura Fraga de Almeida Sampaio. São Paulo: Edições Loyola, 1996.

. O que é um autor? In: FOUCAULT, Michel. Ditos e Escritos III: Estética, literatura e pintura, música e cinema. Organização e seleção de textos, Manoel Barros das Motta. Trad. Inês Autran Dourado Barbosa. Rio de Janeiro: Forense Universitária, 2009, p. 264-298.

KOSTER, Helmut. Introdução ao Novo Testamento, volume I: história, cultura e religião do período helenístico. Trad. Euclides Luiz Calloni. São Paulo: Paulus, 2005a.

. The Silence of the Apostle. In: SHOWALTER, Daniel N.; FRIESEN, Steven F. (orgs). Urban Religion In Roman Corinth: Interdisciplinary Approaches. Cambridge: Distributed by Havard University Press for Havard Theological Studies Havard Divinity School, 2005b, p. 339-349.

MACHADO, Jonas. O misticismo apocalíptico do apóstolo Paulo: um novo olhar nas Cartas aos Coríntios na perspectiva da experiência religiosa. São Paulo: Paulus, 2015. 
MURPHY-O'CONNOR, Jerome. Paulo: biografia crítica. Trad. Barbara Theoto Lambert. São Paulo: Edições Loyola, 2015.

PATTERSON, Stephen J. The Gospel of Thomas and Christian Origins: Essays on the Fifth Gospel. Boston: Brill, 2013.

SELVATICI, Monica. Corpo e Religião: Paulo de Tarso e a experiência de conversão ao movimento cristão. Reflexus - Revista de Teologia e Ciências das Religiões, Vitória, n. VI, v. 8, p. 119-129, 2012/1.

VIECELI, Ana Paula. Arquitetura da loucura na Antiguidade Clássica: a loucura ritual, o teatro e o templo da cura. Anais - II Congresso de Pesquisa e Extensão da FSG, Caxias do Sul, v. 2, n. 2, p. 46-64, 2014.

\section{Notas}

'Selvatici (2012, p. 122) destaca alguns problemas na designação do termo "conversão" à experiência de Paulo. Segundo a autora, para os judeus do Período do Segundo Templo, a palavra se aplicava à conversão de um gentio ao judaísmo, o que corresponderia à transformação de uma vida de idolatria e imoralidades em uma conduta de virtude e temor ao Deus de Israel. Paulo, no entanto, não teria se convertido de uma religião a outra - o que torna a aplicação do termo equivocada. Por outro lado, mesmo que não tenha deixado de ser judeu, sua visão do Cristo Ressuscitado acabou levando-o a reavaliar seu judaísmo, transformando muitas de suas conviç̧ões.

${ }^{2}$ Como salienta Dunn (2017, p. 181-182), em 1 Tessalonicenses 4:15 e 1 Coríntios 15:51, Paulo parece acreditar que ainda estaria vivo quando Cristo retornasse, além de outras passagens de suas cartas que evidenciam a crença na aproximação desse fim, como Romanos 13:12.

${ }^{3}$ Nossa utilização da sentença "a morte redentora de Cristo", em poucas palavras, se refere à compreensão de Paulo de que Jesus, o messias, teria sido morto em razão de expiar os pecados da humanidade. $\mathrm{O}$ termo grego apolútrōsis, usado por Paulo em 1 Coríntios 1:30, se traduz, conforme Gingrich (1984, p. 31), por "redenção (lit. comprar de volta), libertação, resgate, soltura, livramento".

${ }^{4}$ Para Gingrich (1984), Paulo utiliza a palavra "gentios" (1 Coríntios 1:23; 5:1; 12:2) e "gregos" (1 Coríntios 1:22.24; 10:32; 12:13), aparentemente, como sinônimos.

${ }^{5}$ Cf. 1 Coríntios 1:18,21,23,25; 2:14; 3:19.

'O termo advém da união de lógos, que se traduz por "palavra" (GINGRICH, 1984, p. 127), a sōtēría, "salvação, libertação, preservação" (GINGRICH, 1984, p. 202). 
Paulo utiliza o termo tanto em sentido corriqueiro quanto para se referir à salvação realizada por Cristo.

${ }^{7}$ Cf. 1 Coríntios 1:17,19,20,21,21,22,24,30; 2:1,4,5,6,6,7,13; 3:19; $12: 8$.

${ }^{8}$ "Evidentemente, Paulo não permite que tais declarações carreguem a autoridade de Jesus, e assim ele nega aos coríntios o direito de confiar em tais declarações. Para Paulo, o mistério que está sendo revelado nunca é um dizer de Jesus, mas a mensagem da cruz (1 Coríntios 1: 17-18). Embora Paulo conheça tais ditos de Jesus, eles nunca são chamados de autoridades salvadoras. Sua mensagem de Cristo crucificado não permite que Jesus seja uma autoridade para declarações que têm o poder para salvar" (KOESTER, 2005b, p. 345, tradução nossa). 